LBL- -25255

DE88 012025

\title{
INSERTION DEVICE VACUUM SYSTEM DESIGNS
}

\author{
Egon Hoyer \\ Lawrence Berkeley Laboratory, University of California, Berkeley, CA 94720
}

\begin{abstract}
Synchrotron light source inserrion device vacuum systems now in operation and systems proposed for the funtre are reviewed. An overview of insertion devices is given ard four generic vacuum chamber designs, transition section design and pumping considerarions are discussed. Examples of vacuum chamber systems are presented.
\end{abstract}

\section{INTRODUCTION}

During the past 10 years increased flux and brightness of synchrotron radiation has been achieved from electron storage rings with the development and installation of insertion devices (wigglers, undulators and wave-length shifters) at these facilities! Successful vacuum system design of these devices has contributed to this development. With the advent, in the near future, of the 3rd generation syochrotron light facilities, those designed as low emittance electron storage rings expressly for wiggler/undulator sources, vacuum system design for these insertion devices will be challenging.

The importance of vacuum system design for insertion devices can be appreciated when reviewing the development of insertion devices. Most insertion devices built to date can be grouped according to the rechnology used in the magnetic field structure construction. These include conventional electromagnet, superconducting magnet and permanent magnet technologies.

Figure I summarizes peak fieid performance for period length of various devices built and operated to dare $23,4,5,6,7,8,9,10,11$. Dashed curves show approximately the present range of performance of insertion devices for the various construction technologies. Insertion devices built with conventional electromagnet technology are generally longer period length devices. At long period lengths these devices have peak fields near the saturation induction of iron and at shorter period lengths the peak field decreased due to limitations in coil cooling. Superconducting magnet technology conseruction generally is limited in peak field by critical current density in the superconductor. Systems of this type generally tend to be complex and expensive. Wave length shifters use this technology because very high fields are possible. Peak Gields obtained in insertion devices built with permanent magnet technology are dependent on the permanent magnet materials used and geometry. Devices using rareearth-Cobalt and Neodymium-Iron magnetic materials have demonstrated high peak Gields with shor period length. Generally, peak field performance of conventional and supenconducting magnets is inverse to the magnet gap if iron sanuration, coil cooling or critical current density are not limiting whereas with permanent magnet insertion devices the field is approximately proportional to the inverse exponential of the

This work was supported by the U.S. Department of Energy, Office of Energy Research, under Contract DE-AC03-76SF00098. 
magnetic gap with highest fields obtained with smallest gaps. Despite the small gap limitarion, most insertion devices to date have been built with this technology, primarily because high peak field can be achieved with short period length with simplicity and economy in design. This paper will primarily address vacuum chamber design for electromagnet and permanent magnet inserrion devices.

The peak field performance of a typical permanent magnet insertion devices, in this case the BL X Wiggler at SSRL, is shown in Figure $2^{9}$. Peak field is plotred both as a function of gap and gap to period ratio which allows scaling of magnetic performance to any period length. The figure shows that peak field of permanent magnet insertion devices is a strong function of gap to period ratio; for a given insertion device period length, the maximum field is achieved with a minimum magnetic gap.

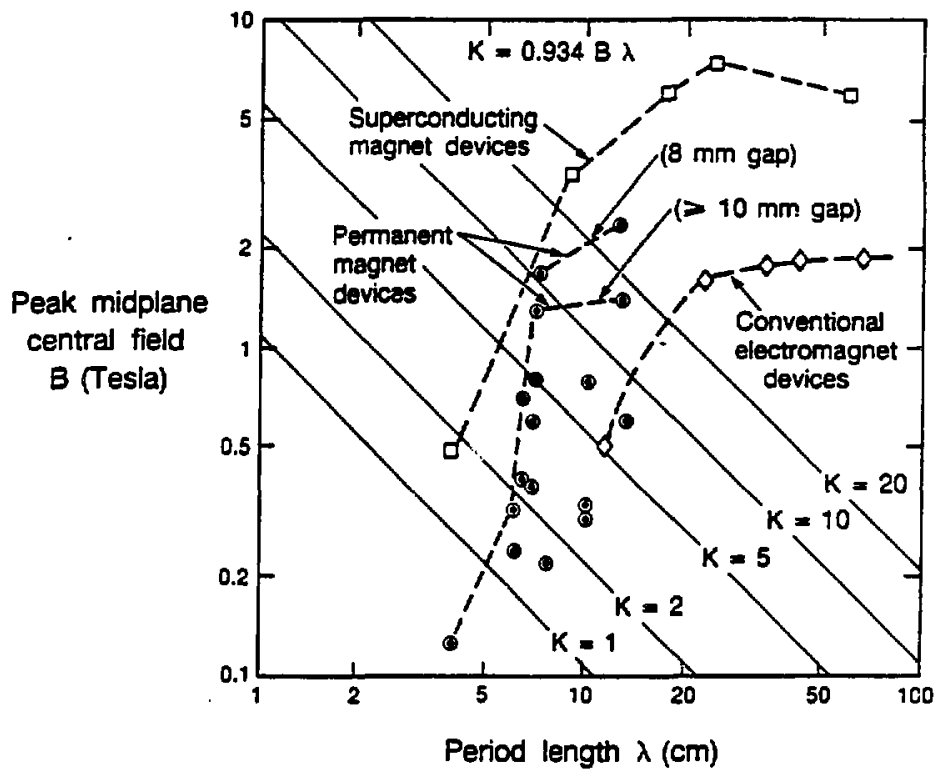

XEL 885-9639

Fig. 1. Peak Midplane Central Field as a Function of Period Length for Operational Planar Insertion Devices. 


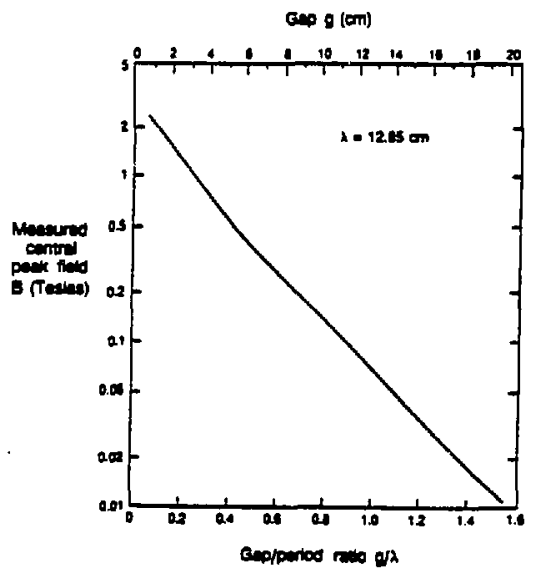

Fig. 2. Magnetic Performance of the BL X Wiggler

\section{VACUUM SYSTEM DESIGN CONSIDERATIONS VACUUM CHAMBER DESIGN}

From the above, generally the main design objective for permanent magnet insertion device design is to schieve the highest possible field which implies the smallest possible magnetic gap. In this case, what is desired is the mirimum material thickness between the magneac structure gap and the beam apernure. This implies a minimum vacuum chamber or image current sheet/outgassing barrier thickness.

A variety of generic vacuum chamber desiga possibilities can be considered for insertion device vacuum chambers which meet the requirement of minimum thickness for permanent magnet insertion devices and are shown in Table I. The design approaches consider the magnetic struchure either in $\alpha$ out of the vacuum chamber, the magnetic structure either bare or canned and the vacuum chamber of either a rigid or a flexible configuration.

TableI. Insertion Device Vacuum Chamber Design Possibilities

Design

Type

Magnetic Structure -

in or out of the vacuum

\section{Magnedic Strucnur-} outer construction
Vacuum

Chamber

Construction

A
C

Out
Out
In
In

Bare
Bare
Bare
Canned

Rigid Flexible Rigid Rigid 
Examples of the various vacuum chamber design possibilities suggested in Table I are described in more detail below.

\section{Design Type A:}

This fixed vacuum chamber design is the simplest of the approaches shown and has been used most frequently. Table 2 lists a number of chambers that have both been built and/or will be put into operation9,11,12,13,14,15.

Figure 3 shows the SRC chamber for the LBL-SSRL Undulator ${ }^{11}$. Vacuum chamber thicknesses, fabrication tolerances and clearances add up to $5 \mathrm{~mm}$. Figure 4 shows the SSRL BL X Wiggler vacuum chamber. This design achieved 2.9 mm total of the vacuum chamber thicknesses [ $2 \times 0.75 \mathrm{~mm}$ ], fabrication tolerances $[2 \times 0.53 \mathrm{~mm}]$, and clearances $[0.3 \mathrm{~mm}]^{9}$. Figure 5 shows the NSLS TOK vacuum chamber which toals to $3.2 \mathrm{~mm}$ for chamber thiclonesses, fabrication tolerances and clearances 13 . Figure 6 shows the approach taken at DESY where they have used the technology developed for the thin booster vacuum chamber and applied it to a wiggler chamber ${ }^{14}$.

Based on Table 2, welded stainless steel vacuum chambers 2 to 3 meter long, can achieve flamesses of 0.4 to $0.8 \mathrm{~mm}$. Typical loss of aperrure due to chamber thickness, fabrication tolerance and clearance is 3 to $5 \mathrm{~mm}$. To date, welded aluminum construction for this application has not approached this performance.

Table 3 lists fixed aperture vacuum chambers for facilities now under construction or proposed 15,16,17. These designs are for the most part conceptual and achieving the required tolerances will be challenging.

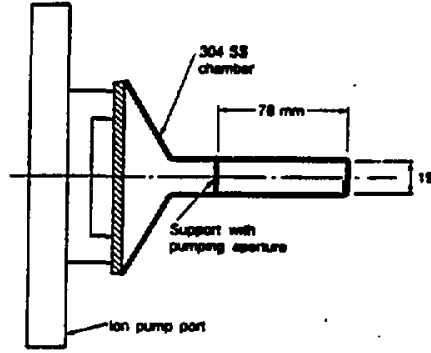

Fig.3. SRC Vacuum Chamber Section for the Undulator

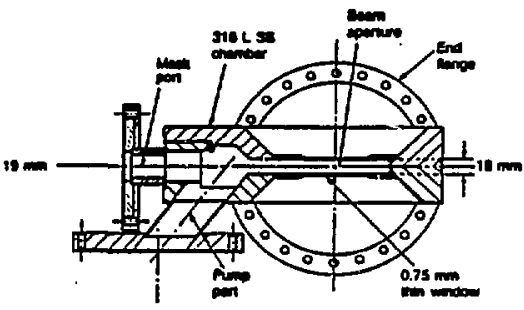

Fig. 4. SSRL BL $X$ Wiggler Vacuum Chamber Section 
TAMLE 2. EXISTO FXED APERTUAE MSEATION DEYCE YACUUN CHAMBEAS

\begin{tabular}{|c|c|c|c|c|c|c|c|c|c|}
\hline PActTr & Cavice & 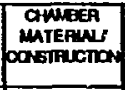 & 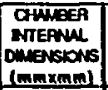 & 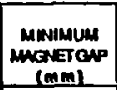 & 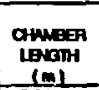 & 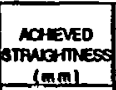 & $\begin{array}{l}\text { PUMPWG } \\
\text { NCHWAER }\end{array}$ & 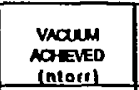 & $\begin{array}{l}\text { FEATURES } \\
\text { CONMENTS }\end{array}$ \\
\hline $\begin{array}{c}805 \\
0750 \times y \\
\end{array}$ & 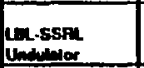 & $\begin{array}{l}304 \\
\text { sishinandand }\end{array}$ & $10 \times 76$ & 24 & $\begin{array}{l}2.23 \mathrm{~m} \\
\text { hendeden } \\
\text { wendians }\end{array}$ & $0.31 \mathrm{~mm}$ & $\begin{array}{l}\text { Yes - } 1 \\
60 \text { vene lon Pumpe }\end{array}$ & $\begin{array}{r}0.5 \text { - no bown } \\
1.0 \text { with } 18.5 \mathrm{mn} \\
\end{array}$ & $\begin{array}{l}\text { perforeved wail } \\
\text { iedill daering } \\
\text { electrodes }\end{array}$ \\
\hline 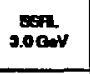 & 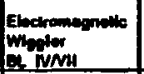 & $\begin{array}{l}\text { soes } \\
\text { Aluminum! } \\
\text { weded }\end{array}$ & $18 \times 127$ & 30 & $2.04 \mathrm{~mm}$ & $>10 \mathrm{~mm}$ & Nb & $?$ & $\begin{array}{l}\text { Ouler reolun } \\
\text { wele cooind }\end{array}$ \\
\hline $\begin{array}{l}\text { ser. } \\
\text { novit }\end{array}$ & 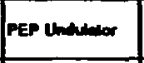 & 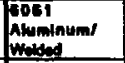 & $91 \times 92$ & 44 & $222 \mathrm{~m}$ & $0.6 \mathrm{~mm}$ & 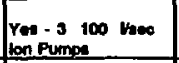 & $?$ & $\begin{array}{l}\text { Ouler reolune } \\
\text { witer cooled }\end{array}$ \\
\hline $\begin{array}{c}\mathrm{ESh} \\
3.0 \mathrm{eO}\end{array}$ & DYY & $\begin{array}{l}\text { Soct } \\
\text { Aluminum/ } \\
\text { itheded }\end{array}$ & $18 \times 127$ & jo & $204 \mathrm{~m}$ & $21.0 \mathrm{~mm}$ & W & 7 & $\begin{array}{l}\text { Ouler redhe } \\
\text { veler cooled }\end{array}$ \\
\hline $\begin{array}{l}8 \mathrm{FL} \\
3.0 \mathrm{c}: \mathrm{V}\end{array}$ & $\begin{array}{l}\text { Le-BFL-LLM } \\
\mathrm{Lx}_{\mathrm{X}}\end{array}$ & $\begin{array}{l}\text { 316L } \\
\text { SSTWed }\end{array}$ & $10 \times 222$ & $\begin{aligned} & 21 \\
\text { e Poln } & \end{aligned}$ & $2.25 \mathrm{~m}$ & $0.55 \mathrm{~mm}$ & 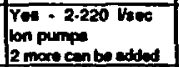 & 7 & 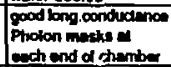 \\
\hline nas & 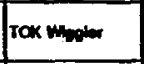 & 304 & $27.5 \times 00$ & $\begin{array}{l}30.0 \\
\text { ctpoles }\end{array}$ & $2.22 \mathrm{~m}$ & $0.37 \mathrm{~mm}$ & 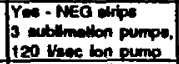 & 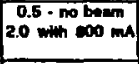 & \\
\hline $\begin{array}{l}\text { Mas } \\
270 \mathrm{~N}\end{array}$ & $\begin{array}{l}x-1 \\
\text { Untalerer }\end{array}$ & $\begin{array}{l}318 \mathrm{~L} \\
\sin \text { weded }\end{array}$ & $27 \times 00$ & 30 & $0.24 \mathrm{~m}$ & $0.04 \mathrm{~mm}$ & 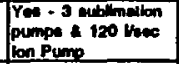 & 7 & \\
\hline $\begin{array}{l}\text { Marua } \\
\text { sacy }\end{array}$ & main & ssweded & $?$ & $?$ & $2.5 \mathrm{~m}$ & 7 & ib & 1 & 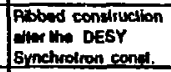 \\
\hline $\begin{array}{l}\text { aress } \\
\text { s.oove }\end{array}$ & $\begin{array}{l}3.3 \mathrm{~cm} \\
\text { APS Linduntor }\end{array}$ & 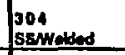 & $12 \times 81$ & $?$ & $24 \mathrm{~m}$ & st.0s mm & $\mathbf{W b}$ & 7 & $\begin{array}{l}\text { Comploiod but not } \\
\text { insillied }\end{array}$ \\
\hline $\begin{array}{l}0.258 \\
5.0 \mathrm{chl}\end{array}$ & $\begin{array}{l}3.9 \mathrm{~cm} \\
\text { APS Undinder }\end{array}$ & $\begin{array}{l}304 \\
\text { ssineded }\end{array}$ & $12 \times 48$ & 7 & $2.4 \mathrm{~m}$ & $0.61 \mathrm{~mm}$ & $\mathbf{H b}$ & $?$ & in fab \\
\hline
\end{tabular}




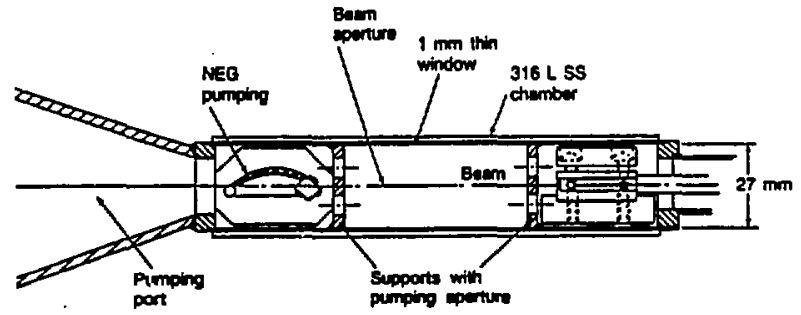

Fig.5. NSLS TOK Vacuum Chamber

Fig.6.

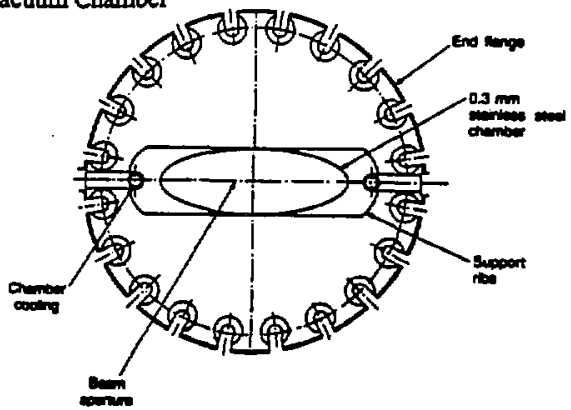

Figure 7 shows a small experimental exmuded vacuum chamber built by the APS group that was clamped rigidly to a continuous support structure and found to be straight within $0.23 \mathrm{~mm}$ over a $5.2 \mathrm{~m}$ length 15 . Figure 8 shows a conceptual crosssection of the insertion device vacuum chambers for the Advanced Light Source. 16

Design Type B:

The flexible vacuum chamber has some advantages when compared to the fixed aperture vacuum chamber. In typical electron storage ring operation, the largest beam aperture is needed at injection in the storage ring; thereafier, the beam is damped and then a smaller beam aperture will suffice for stable long lifetime operadion. With the flexible vacuum chamber, the vacuum gap is opened for injection and then closed after the storage ring is filled allowing for a smaller magnetic gap, higher magnetic field, than with a large fixed aperture vacuum chamber. Other advantages include excelleat pumping when both sides of the horizonnal aperture are open and the option, when storage ring operation bas difficulties, to open the chamber and operate at a larger gap. With a flexible chamber design, from start-up through dedicated operation, only one chamber is required. This is an altemative to using larger gap chambers at start-up and then recrofiting with smaller gap chamber for produccion operation that some of the new facilicies are presently proposing. To date, the flexible vacuum chamber has been much expensive than a single rigid chamber. 
TADLE 3. PROPOSED FIXED APEATLAE MEEATION DEVICE VACUUA CHAMBERS

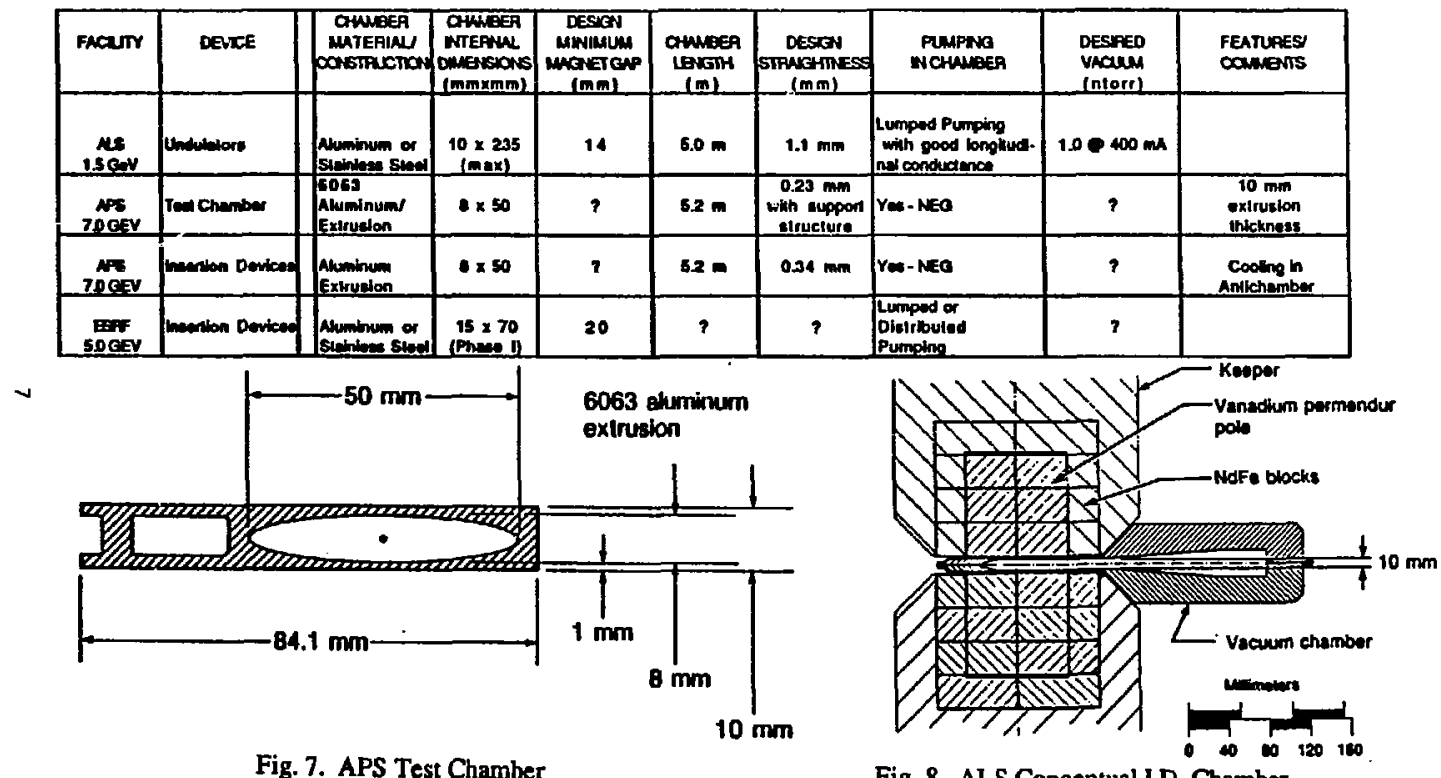

Fig. 7. APS Test Chamber

Fig. 8. ALS Conceptual I.D. Chamber 
The vacuum chamber of the Beam Line VI Wiggler at SSRL is an example of this type and is shown in Figure 98. Chamber thickness at the aperrure is 4mm which has been scalloped out to $1 \mathrm{~mm}$ thickness at the pole locations. Fabrication of the aperture chamber sections resulted in the surfaces flatness to within 0.5 and $1.0 \mathrm{~mm}$. Loss of apermure due to thicknesses, fabrication tolerances and clearances was $4 \mathrm{~mm}$. Figure 9 shows the two omega joints which give the chamber its flexibility. These joints, $316 \mathrm{SS}, 7.5 \mathrm{~cm}$ nominal dianeter and race track plan, $76 \mathrm{~cm}$ by $254 \mathrm{~cm}$, allow the chamber to open to $1.8 \mathrm{~cm}$ for injection and to close to a minimum of $0.5 \mathrm{~cm}$. The vacuum chamber is driven with a'separate drive system.

A variation of the Beam line VI vacuum chamber is being explored by the BESSY group for their proposed BESSY II facility 18 . The proposed conceptual design is shown in Figure 10. This design proposes only 1 omega joint, $10 \mathrm{~mm}$ of motion and a preloaded vacuum chamber which is normally open to the largest gap and is closed to smaller gaps with the magnetic structure drive system.

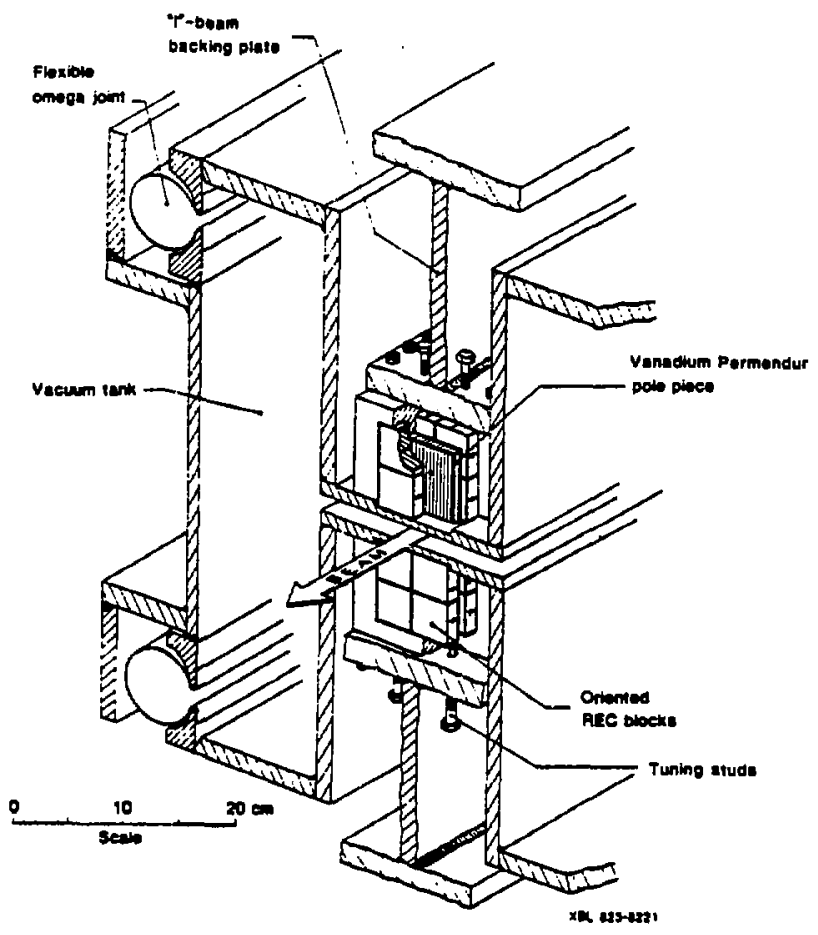

Fig.9. Beam Line VI Wiggler Flexible Vacuum Chamber 


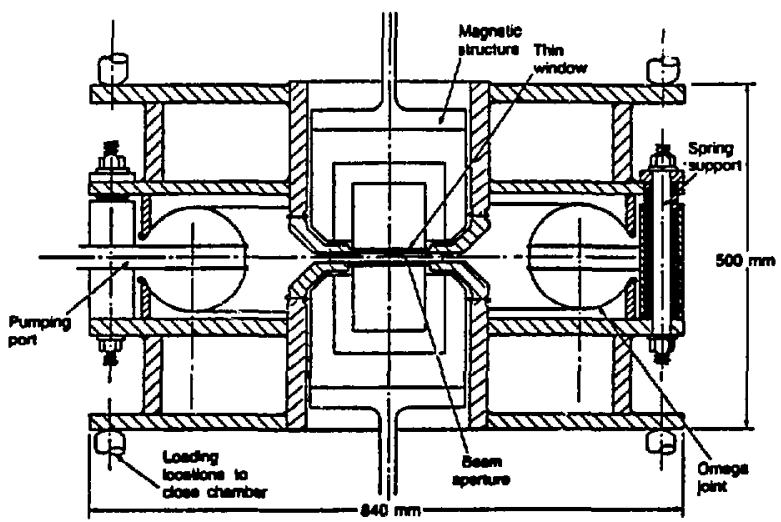

Fig. 10. Proposed BESSY II Inserion Device Vacuum Chamber

\section{Design Type C:}

This type of configuration has the insertion device magnetic structure inside the vacuum chamber with thin metallic sheets placed between the beam aperture and magretic structure to allow for the flow of beam image currents and to reduce the amount of gas in the beam aperture. This type of configuration gives the minimum operational magnetic gap configuration which might be very important for very short period length devices. Disadvantages of this system are that a high pumping speed is required, thexe is probably limited access to the magnetic structure after it is installed in the vacuum chamber - local adjusments would be virnally impossible to make, and vacuum bakeout must be very carefully monitored and probably done at reduced temperanure so as to not induce ineversible loss of magnetization in the permanent magnet structure. An SSRL proposal for a 1.Scm period device would use this type of construction ${ }^{2}$.

\section{Design Type D:}

This configuration is similar to $C$ in that the magnetic structure is placed in the vacuum chamber but the magnetic structure here is enclosed in a thin metallic envelope that is canned and can be at amospheric pressure or at a reduced pressure. The advantages of the system are that very lirele aperture is lost to a vacuum barrier and when compared to the Type $C$ design with less purmping required. Disadvantages are, as in the Type $C$ design. that there is limited access to the magnetic structure and the bakeout must be very carefully monitored and probably done at reduced temperanure.

Examples of this construction are the early NSLS UV Ring FEL magnetic structure and the BESSY Muldipole Wiggler shown in Figure 112.5 . The BESSY device feanures an $80 \mathrm{~cm}$ diameter by 2.5 meter long vacuum chamber which is pumped with a 2400 $1 / \mathrm{sec}$ turbomolecular pump. The vacuum bariers are $0.5 \mathrm{~mm}$ thick and the fabrication achieved flatnesses of $2 \mathrm{~mm}$ on one side and less than $1 \mathrm{~mm}$ on the other side. 


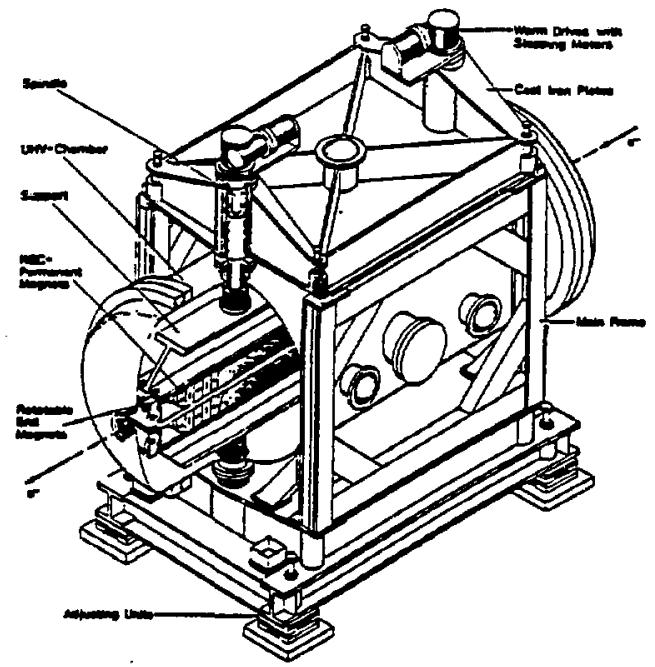

Fig. 11. BESSY Multipole Wiggler Vacuum System

TRANSITION SECTION DESIGN

The transition sections are the connections between the insertion device vacuum chamber and the storage ring vaculvis cinambers. Important design considerations here are that the transicion secrion be compact and that they provide a conducting surface for the beam image currents from the storage ring vacuum chamber to the insertion device chamber in such a way as to minimize higher order mode losses.

Transition sections may include:

1. An expansion joint which allows for expansion and contraction of both the stcrage ring and insertion device vacuum chambers and for alignment for these components.

2. Beam position monitors for beam location.

3. Masks for intercepting unwanued rndiation from the adjacent magnets.

4. Pumping at the masis for betrer vacuum.

5. Shutoff valve with "smooth" RF section when open.

6. Instrumenarion for beam diagnosics.

7. Appropriate configurations berween the storge sing chamber and inserrion device chamber to minimize higher order mode losses.

Ar example cansition section design is shown in Figure $12^{9}$. The bellows allows for $32 \mathrm{~mm}$ of compression for bakeout and simultanenusly a $+/-3 \mathrm{~mm}$ cansverse 
movement. The low loss RF transition includes a tapered section and capacitively coupled interleaved surfaces. Beam position is monitored with a four button arrangement mounted to the insertion device nactum chamber. In this design, masking for radiation from the adjacent magnets is accouplished with a mask and pump located just inside the end of the insertion device vacuum chamber.
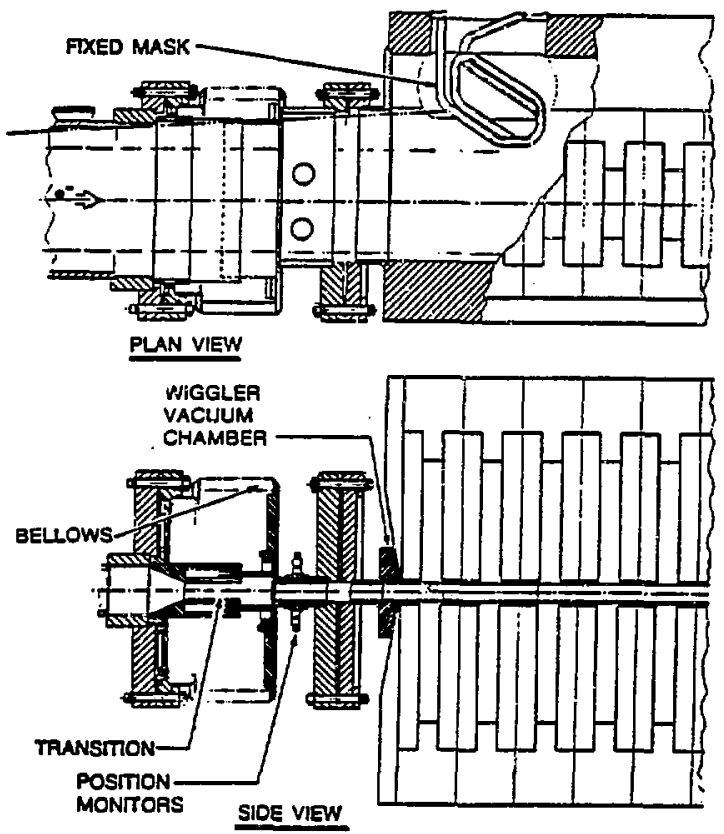

Figure 12: Beam Line $X$ Wiggler Transition Design

\section{PUMPING SYSTFM DESIGN}

Base pressure and species of the residual gas in the insertion device vacuum chamber are imporant for proper operation of the synchrotron radiation source. Typically for an accelerator, the gas-scattering lifecime is inversely proportional both to the base pressure and to approximately the square of the atomic number of the residual gas species 19 .

Gas loads in these systems are made up of thermal desorption of gas from the chamber and transition section surfaces but are dominared by photon induced desorption of surfaces due to radiation from the adjacent magnets striking surfaces in the inserion device region. Due to photon stimulated desorption suggests that configuration design and locacion of pumping should be such that high conductance is 
achieved from the dominant photon desorped surfaces to the pumped system so that the best possible low base pressure is achieved. High atomic number gases and contaminants need to be held to a minimum.

Pumping systems used for inserion device vacuum systems, now in operaion include ion pumps, titanium sublimation pumps, non evaporable getter pumps, and turbomolecular pumps.

\section{REFERENCES}

1. H. Winick, Synchrotron Radiation, Scientific American, Vol. 257, No. 5 , (1987).

2. G. Brown, et al., Wiggler and Undulator Magnets - A Review, NIM, Vol. 208, (1983).

3. G. Kornyukhin, et al., The Magnetic System of an Optical Klystron Using SmCo Permanent Magnets, NIM, Vol 208, (1983).

4. E. Gluskin, et al., First Experiments with SR from the 75 KG Superconducting Wiggler on the VEPP-2M Storage Ring, NMM, Vol. A246, (1985).

5. W. Gudat, et al., An Undulato:/Multipole Wiggler for the BESSY Storage Ring, NM, Vol. A245, (1985).

6. P. Guertler, Installation and Test of a Multipole Wiggler in DORIS II, NIM, Vol. A246. (1985)

7. N. Vinokurov, Insertion Device Development at Novosibirsk, NIM, Vol. A246, (1985).

8. E. Hoyer, et al., The Beam Line VI REC-Hybrid Wiggler for SSRL, IEEE Trans. NS-30, 3118, (1983).

9. E. Hoyer, et al., The Beam Line X NdFe-Steel Hybrid Wiggler for SSRL, IEEE PAC, 87CH2387-9, (1987).

10. B. Kincaid, AT\&T, private communication

11. R. Boyce, SSRL, private communicarion.

12. M. Green, SRC, private communication.

13. J. Schuchman, NSLS, private communication.

14. J. Pflueger, DESY, private communication.

15. J. Vicaro, private communication.

16. 1-2 GeV Synchrorron Radiation Source, Conceprual Design Reporr, LBL Publication PUB-5172, (1986)

17. P. Elleaume, ESRF, private communication.

18. A. Gaupp, E. Hoyer, Conceprual Design of a Variable Aperture Vacuum Chamber, BESSY Intemal Note DUA ]:[OC.gaupp] VAC.; (1987).

19. M.S. Zisman, et al., ZAP USER'S MANUAL, LBL-21270, (1986). 